\title{
Perancangan Balancing Robot Beroda Dua Dengan Metode Pengendali PID Berbasis Arduino Nano
}

\author{
Marfanri Lamatenggo \\ Prodi Teknik Elektro \\ Universitas Negeri Gorontalo \\ Gorontalo, Indonesia \\ marfanrylamatenggo@gmail.com
}

\author{
Ifan Wiranto \\ Prodi Teknik Elektro \\ Universitas Negeri Gorontalo \\ Gorontalo, Indonesia \\ ifan_te@ung.ac.id
}

\author{
Wrastawa Ridwan \\ Prodi Teknik Elektro \\ Universitas Negeri Gorontalo \\ Gorontalo, Indonesia \\ wridwan@ung.ac.id
}

\begin{tabular}{ll}
\hline Diterima : Juni 2020 \\
Disetujui & : Juni 2020 \\
Dipublikasi : Juli 2020
\end{tabular}

Abstrak - Balancing robot adalah robot beroda dua dengan badan robot diasumsikan sebagai pendulum terbalik. Sistem ini tidak stabil karena ketika kereta beroda diberi gangguan dari luar maka pendulum akan jatuh. Untuk mempertahankan agar tidak jatuh maka posisi pendulum harus dipertahankan seimbang. Oleh karena dibutuhkan suatu sistem kendali yang berfungsi untuk mempertahankan posisi pemdulum. Permasalahan yang ada disini adalah bagaimana membuat robot tetap stabil tegak lurus dengan permukaan bumi. Pada penelitian ini ditawarkan metode kendali PID (Proporsional, Integral dan Derivatif) berbasis Arduino Nano. Dalam pembuatan Balancing robot menggunakan sensor GY-521 MPU-6050 Module untuk mendeteksi kemiringan robot, dengan penggerak robotnya menggunakan motor DC $6 \mathrm{~V} 620$ RPM gearbox 25 ga370. Hasil yang didapat dari penelitian ini adalah Balancing robot dapat menyeimbangkan diri pada ACC $\mathrm{Y}-220^{\circ}$ dan ACC Z $-40^{\circ}$. Pengendali PID ditanamkan pada mikrokontroler Arduino nano dengan nilai $K p=60, K i=2.0$ dan $K d=130$.

Kata Kunci-Balancing robot, kendali PID, Arduino nano.

Abstract-Balancing robot is a two-wheels robot with a robot body assumed to be an inverted pendulum. This system is unstable because when the robot is disturbed from outside the pendulum will fall. To keep from falling, the position of the pendulum must be keep in balance. Therefore we need a control system that functions to keep the position of the pemdulum. The problem here is how to make the robot remain stable perpendicular to the surface of the earth. In this study, the PID (Proportional, Integral and Derivative) PID control method based on Arduino Nano. To build the balancing robot, it uses a GY-521 MPU-6050 module sensor to detect the tilt of the robot, with the robot drive using a DC 6V 620 RPM gearbox 25ga370 motor. The results obtained from this research is the balancing robot can balance itself on Axis Y 220 and Axis Z -40. The PID controller is implanted in Arduino nano with values $K p=60, K i$ $=\mathbf{2 . 0}$ and $K d=130$.

Keywords - Balancing robot, PID controller, Arduino nano.

\section{Pendahuluan}

Pada masa lalu banyak penelitian tentang prinsip kerja pendulum terbalik yang kemudian pada akhirnya mengarah pada penelitian tentang robot beroda dua atau biasa dikenal dengan balancing robot. Kompleksitas dan ketidaktahuan tentang lingkungan dan situasi yang akan dihadapi oleh robot adalah suatu kebutuhan yang rumit baik bagi komponen perangkat keras robot maupun perangkat lunaknya. Robot juga harus memiliki kemampuan untuk mempersepsikan keadaan berdasarkan informasi yang didapati dari sensor yang terkadang tidak akurat. Selain itu, robot juga harus mampu mengambil keputusan tentang pergerakannya.

Dalam beberapa tahun terakhir, telah berkembang teknologi robotika yang menerapkan ide model pendulum terbalik salah satunya yaitu balancing robot yang merupakan model sederhana dari alat transportasi sederhana. Inverted pendulum atau pendulum terbalik adalah pendulum yang terengsel ke kereta beroda yang dapat bergerak maju dan mundur pada bidang horisontal di sepanjang lintasan. Penerapan konsep inverted pendulum dalam dunia robotika dapat dilihat pada balancing mobile robot, yaitu mobile robot dengan dua roda yang roda tersebut diasumsikan sebagai kereta beroda dan badan robot diasumsikan sebagai pendulum [1]. Sistem ini tidak stabil karena ketika kereta beroda diberi gangguan dari luar maka pendulum akan jatuh. Untuk mempertahankan agar tidak jatuh maka posisi pendulum harus dipertahankan seimbang. Oleh karena dibutuhkan suatu sistem kendali yang berfungsi untuk mempertahankan posisi pemdulum. Beberapa penelitian telah dilakukan untuk kendali keseimbangan robot beroda dua, di antaranya menggunakan logika fuzzy [2,3], menggunakan kontrol PID berbasis sensor cahaya [4], menggunakan metode LQR [5], berbasis pada logika fuzzy dan filter Kalman [6], berbasis pada complementary filter dan PID [7].

Pada penelitian ini penulis menggunakan kontroler PID yang berbasis pada Arduino Nano untuk menentukan besarnya kecepatan dan arah putaran motor DC sebagai 
penggerak, berdasarkan sudut kemiringan badan robot terhadap bidang horizontal agar robot beroda dua ini dapat mempertahankan posisinya untuk tetap tegak berdiri. Pemanfaatan Arduino telah banyak dilakukan, diantaranya pada aplikasi sistem peringatan dini [8, 9] dan jam digital penentu waktu sholat [10].

\section{INVERTED PENDULUM}

Inverted Pendulum merupakan pendulum yang berada diatas poros putar (kereta beroda) sehingga menyebabkan tidak seimbang. Ketika pusat massa Inverted Pendulum secara langsung berada diatas poros putar maka poros putar akan tetap diam. Jika poros putar sedang diam dan pusat massa sedikit bergeser dari posisi vertikal, maka pendulum tidak akan kembali ke posisi semula tetapi cenderung mencari posisi keseimbangan baru sehingga pusat massanya berada pada posisi terendah mungkin. Sistem kendali umpan balik yang mengatur poros putar dapat digunakan untuk meyeimbangkan Inverted Pendulum. Kendali yang baik akan membuat pendulum tetap seimbang dengan cara mengendalikan pergerakan poros putar atau kereta beroda dimana pendulum tersebut terpasang. Dapat dilihat pada Gambar 1.

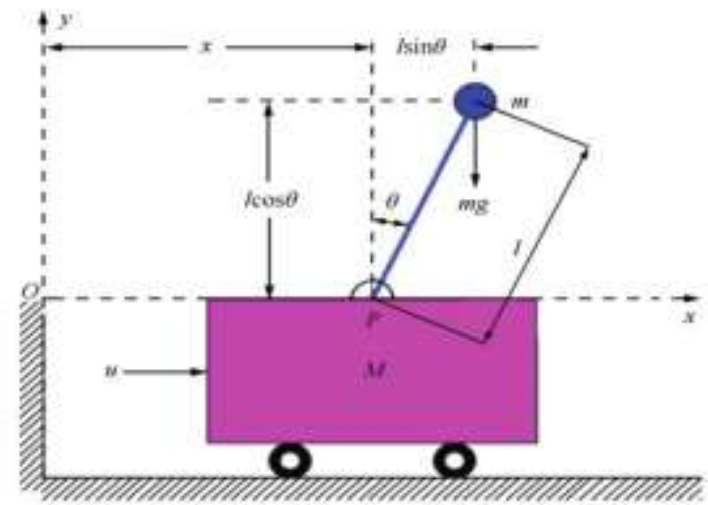

Gambar 1. Inverted Pendulum diatas Kereta Beroda

Model persamaan matematik inverted pendulum dapat dituliskan sebagai berikut. Kesetimbangan gaya pada sistem pada arah $x$ dapat ditulis sebagai,

$M \ddot{x}+m_{p} \ddot{x}_{G}=u$

Di mana pusat gravitasi dari titik massa. Lokasi dari pusat gravitasi dari beban pendulum adalah

$x_{G}=x+l \sin \theta, \quad y_{G}=l \cos \theta$

dengan $l$ adalah panjang tiang pendulum. Subtitusi (2) ke (1) didapatkan:

$\mathrm{M} \ddot{x}+m_{p} \frac{d^{2}}{d t^{2}}(x+l \sin \theta)$

Penyelesaian terhadap persamaan (3) menghasilkan,

$\left(\mathrm{M}+m_{p}\right) \ddot{x}-m_{p} l \dot{\theta}^{2} \sin \theta+m_{p} l \ddot{\theta} \cos \theta=u$

Diketahui persamaan umum torsi terhadap partikel berjarak $l$ dari pusat rotasi dan gaya $F$ adalah

$T=F l$
Komponen-komponen torsi yang bekerja pada pusat massa pendulum adalah,

$$
T_{x}=F_{x} \cos \theta l, \quad T_{y}=F_{y} \sin \theta l
$$

Sehingga resultan kesetimbangan torsi pada pusat massa pendulum,

$F_{x} \cos \theta l-F_{y} \sin \theta l=m_{p} g \sin \theta l$

dengan $F_{x}=m_{p} \ddot{x}_{G}$, dan $F_{y}=m_{p} \ddot{y}_{\mathrm{G}}$ berturut-turut adalah komponen-komponen gaya pada arah $\mathrm{x}$ dan arah $\mathrm{y}$, dan

$\ddot{x}_{G}=m_{p}\left[\ddot{x}-l \dot{\theta}^{2} \sin \theta+l \ddot{\theta} \cos \theta\right]$

$\ddot{y}_{G}=-m_{p}\left[l \dot{\theta}^{2} \cos \theta+l \ddot{\theta} \sin \theta\right]$

Subtitusi persamaan (8) dan (9) ke persamaan (7) menghasilkan,

$m_{p} \ddot{x} \cos \theta+m_{p} l \ddot{\theta}-m_{p} g \sin \theta=0$

Persamaan (4) dan (10) merupakan persamaan yang mendefinisikan gerak dinamik dari sistem pendulum terbalik. Dalam bentuk matriks persamaan-persamaan tersebut dapat dituliskan seperti pada Persamaan (11).

$\left[\begin{array}{l}\ddot{x} \\ \ddot{\theta}\end{array}\right]=\left[\begin{array}{c}\frac{u+m_{p} l \dot{\theta}^{2} \sin \theta-m_{p} g \cos \theta \sin \theta}{M+m_{p}-m_{p} \cos ^{2} \theta} \\ \frac{u \cos \theta-\left(M+m_{p}\right) g \sin \theta+m_{p} l \dot{\theta}^{2} \cos \theta \sin \theta}{-m_{p} l \cos ^{2} \theta+\left(M+m_{p}\right) l}\end{array}\right]$

Keterangan:

: Posisi linear kereta $(m)$

$\dot{x}$ : Kecepatan linear kereta $(\mathrm{m} / \mathrm{s})$

$\ddot{x}$ : Percepatan linear kereta $(\mathrm{m} / \mathrm{s} 2)$

: Posisi angular pendulum ( $\mathrm{rad})$

$\dot{\theta}:$ Kecepatan angular pendulum $(\mathrm{rad} / \mathrm{s})$

$\ddot{\theta}$ : Percepatan angular pendulum $(\mathrm{rad} / \mathrm{s} 2)$

: Panjang tiang pendulum $(\mathrm{m})$

$g$ : Percepatan gravitasi $(9.8 \mathrm{~m} / \mathrm{s} 2)$

$u$ : Input sistem $(N)$

$M$ : Massa kereta $(\mathrm{kg})$

$m_{p}:$ Massa beban pendulum $(\mathrm{kg})$

$x G$ : Koordinat pusat massa beban pada $\mathrm{x}(\mathrm{m})$

$y G$ : Koordinat pusat massa beban pada y $(m)$

Persamaan (11) adalah persamaan nonlinear, apabila sudut $\theta$ cukup kecil (kurang dari $15^{\circ}$ ) maka persamaan (11) menjadi persamaan linier [11] seperti pada Persamaan (12), sehingga kontrol PID bisa diterapkan.

$\left[\begin{array}{l}\ddot{x} \\ \ddot{\theta}\end{array}\right]=\left[\begin{array}{c}\frac{u}{M+m_{p}} \\ u\end{array}\right]$

Dasar untuk membuat robot beroda dua dapat setimbang yaitu dengan cara mengendalikan roda searah dengan arah jatuhnya bagian atas sebuah robot Apabila proses tersebut dapat terlaksana maka robot tersebut dapat setimbang. Saat balancing robot beroda dua condong kedepan atau miring ke kanan maka tindakan yang perlu dilaksanakan adalah motor bergerak searah dengan arah kemiringan yang terjadi, sehingga robot akan kembali tegak lurus dengan permukaan 
bidang datar. Gaya yang digunakan untuk menyeimbangkan robot didapat dari putaran roda yang dihasilkan dari motor.

\section{KONTROL PROPORSIONAL, INTEGRAL, DERIVATIF (PID)}

Kontrol Proportional, Integral dan Derivatif (PID) merupakan kontroler mekanisme umpan balik yang biasanya dipakai pada sistem kontrol industri. Sebuah kontroler PID secara kontinyu menghitung nilai kesalahan sebagai beda antara setpoint yang diinginkan dan variabel proses terukur. Kontroler mencoba untuk meminimalkan nilai kesalahan setiap waktu.Komponen kontrol PID ini terdiri dari tiga jenis yaitu Proportional, Integratif dan Derivatif. Ketiganya dapat dipakai bersamaan maupun sendiri-sendiri tergantung dari respon yang kita inginkan terhadap suatu plant. Penggunaan kontrol Proporsional (P) memiliki berbagai keterbatasan karena sifat kontrol yang tidak dinamik ini. Walaupun demikian dalam aplikasiaplikasi dasar yang sederhana kontrol $\mathrm{P}$ ini cukup mampu untuk memperbaiki respon transien. Pengontrol proporsional memiliki keluaran yang sebanding/proporsional dengan besarnya sinyal kesalahan (selisih antara besaran yang diinginkan dengan harga aktualnya).Pengontrol Integral (I) berfungsi menghasilkan respon sistem yang memiliki kesalahan keadaan mantap nol (Error Steady State $=0$ ). Jika sebuah pengontrol tidak memiliki unsur integrator, pengontrol proporsional tidak mampu menjamin keluaran sistem dengan kesalahan keadaan mantapnya nol.

Keluaran pengontrol diferensial (D) memiliki sifat seperti halnya suatu operasi derivatif. Perubahan yang mendadak pada masukan pengontrol akan mengakibatkan perubahan yang sangat besar dan cepat. Ketika masukannya tidak mengalami perubahan, keluaran pengontrol juga tidak mengalami perubahan, sedangkan apabila sinyal masukan berubah mendadak dan menaik (berbentuk fungsi step), keluaran menghasilkan sinyal berbentuk impuls. Jika sinyal masukan berubah naik secara perlahan (fungsi ramp), keluarannya justru merupakan fungsi step yang besar magnitudenya sangat dipengaruhi oleh kecepatan naik dari fungsi ramp dan factor konstanta $\mathrm{K}_{\mathrm{d}}$.Kontrol Derivatif hanya berubah saat ada perubahan error sehingga saat error statis kontrol ini tidak akan bereaksi, hal ini pula yang menyebabkan kontroler Derivative tidak dapat dipakai sendiri.

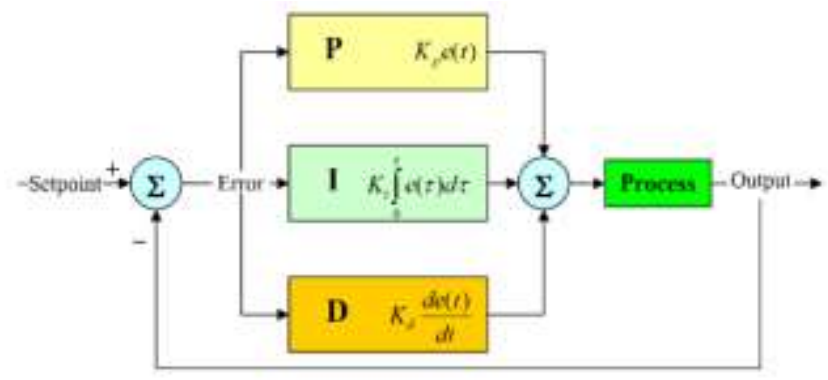

Gambar 2. Diagram alir PID

Berdasarkan Gambar 2, ketiga parameter dapat dijumlahkan sehingga persamaan kendali PID didapat sebagai berikut.
$u(t)=\mathrm{K}_{p} e(t)+\mathrm{K}_{\mathrm{i}} \int_{0}^{1} e(t) d t+K_{d} \frac{d e(t)}{d t}$

atau

$u(t)=\mathrm{K}_{p}\left(e(t)+\frac{1}{\mathrm{~T}_{\mathrm{i}}} \int_{0}^{t} e(t) d t+\mathrm{T}_{\mathrm{d}} \frac{d e(t)}{d t}\right)$

Dengan:

$u(t)=$ sinyal keluaran pengendali PID

$K_{p}=$ konstanta proporsional

$T_{i}=$ waktu integral

$T_{d}=$ waktu derivatif

$K_{i}=$ konstanta integral

$K_{d}=$ konstanta derivatif

$e(t)=$ sinyal kesalahan $=$ referensi - output

Berdasarkan karakteristik pengontrol ini, pengontrol diferensial umumnya dipakai untuk mempercepat respon awal suatu sistem, tetapi tidak memperkecil kesalahan pada keadaan tunaknya. Kerja pengontrol diferensial hanyalah efektif pada lingkup yang sempit, yaitu pada periode peralihan. Oleh sebab itu pengontrol diferensial tidak pernah digunakan tanpa ada kontroler lainnya [12].

\section{Hasil dan Pembahasan}

Pada tahap implementasi, penelitian ini dibagi kedalam dua bagian yaitu perancangan perangkat keras dan perangkat lunak.

\section{A. Perancangan Perangkat Keras}

Gambar 3, Gambar 4, dan Gambar 5 menunjukkan blok diagram, skema desain mekanik dan skema rangkaian perancangan alat balancing robot.

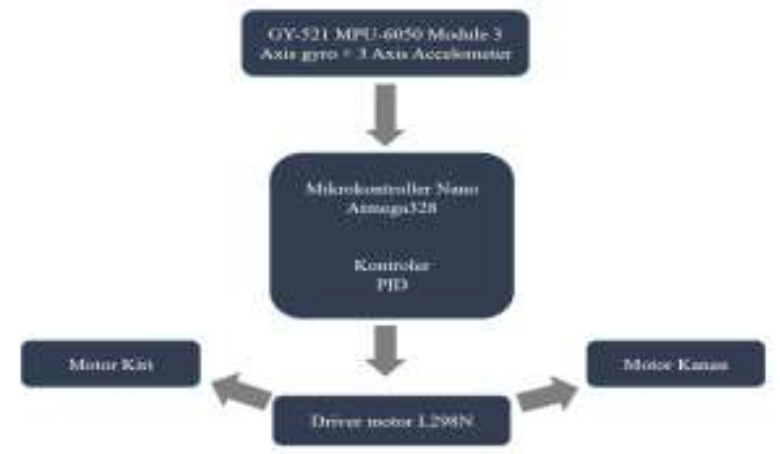

Gambar 3. Gambar Blok Diagram Rancangan Alat

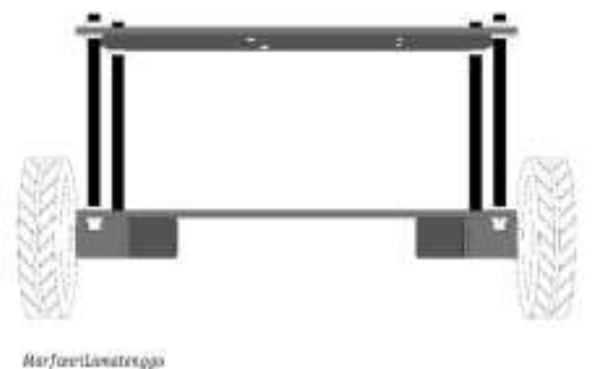

Gambar 4. Skema Desain Mekanik Balancing Robot 


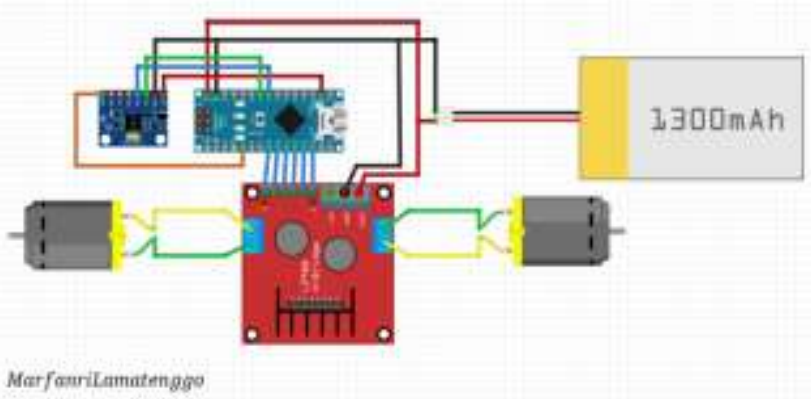

Gambar 5. Skema Rangkaian perancangan alat Balancing Robot

Blok diagram rancangan alat merupakan sistem kendali pada balancing robot. Robot ini nantinya akan meyeimbangkan badannya tampa beban tambahan. Untuk mendeteksi sudut kemiringan robot terhadap permukaan bumi dan kecepatan sudut menggunakan sensor GY-521 MPU-6050 Module 3 Axis gyro + 3 Axis Accelerometer. Seperti yang terlihat pada Gambar 3.3, sensor GY-521 MPU-6050 Module 3 Axis gyro + 3 Axis Accelerometer merupakan alat input menuju arduino nano. Hasil pembacaan dari sensor tersebut nantinya akan dikendalikan oleh PID yang kita set sendiri untuk $\mathrm{Kp}, \mathrm{Kd}$, dan $\mathrm{Ki}$-nya kemudian diolah oleh Arduino Nano kemudian hasilnya akan dikirim ke Driver motor $L 298 \mathrm{~N}$ untuk mengatur kecepatan dan arah putaran motor dc dan bisa dilihat secara fisik.

Sistem mekanik yang baik, mendukung pergerakan robot menjadi lebih baik. Badan robot terbuat dari bahan mika dengan ketebalan $3 \mathrm{~mm}$, dengan roda berdiameter $68 \mathrm{~mm}$ dengan lebar $27 \mathrm{~mm}$ dan sudut ke ujung $12 \mathrm{~mm}$. Dengan posisi sensor berada ditengah badan robot dan baterai berada tepat di atas badan robot (Gambar 5). Gambar 6 menunjukkan hasil rancangan keseluruan dari balancing robot. Pada lantai bawah robot tersebut, dibagian bawah berisi motor driver dan braket $\mathrm{L}$ sebagai penahan motor dc beserta roda, sedangkan bagian atas berisi GY-521 MPU6050 Module 3 Axis gyro +3 Axis Accelerometer dan Arduino Nano. Pada lantai atas berisi Baterai lipo $12 \mathrm{~V}$ 2200mAh 3S 25C XT60 yang berfungsi sebagai catu daya sistem keseluruhan.

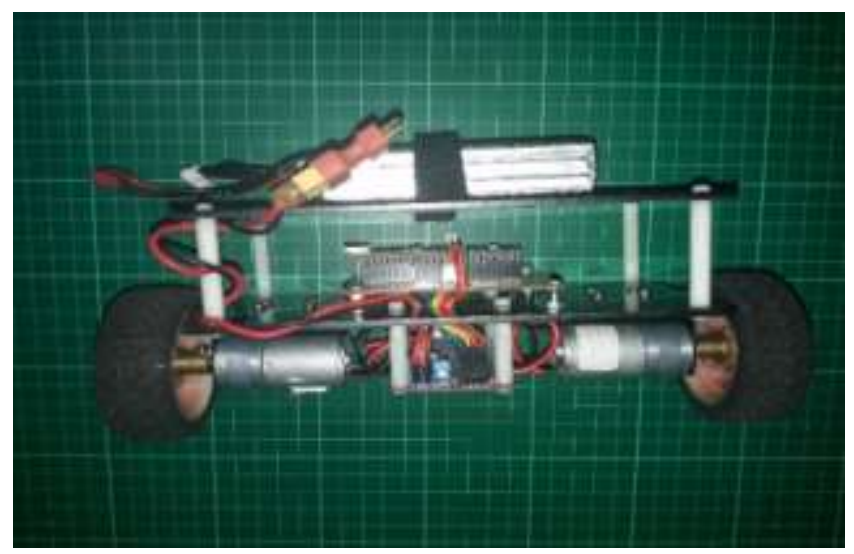

Gambar 6. Hasil Rancangan Balancing Robot

\section{B. Perancangan Perangkat Lunak}

Sebelum memasuki tahap pembuatan kode program untuk rancangan alat, proses kerja alat dibuat dalam bentuk flowchart, yang dapat dilihat pada Gambar 7.

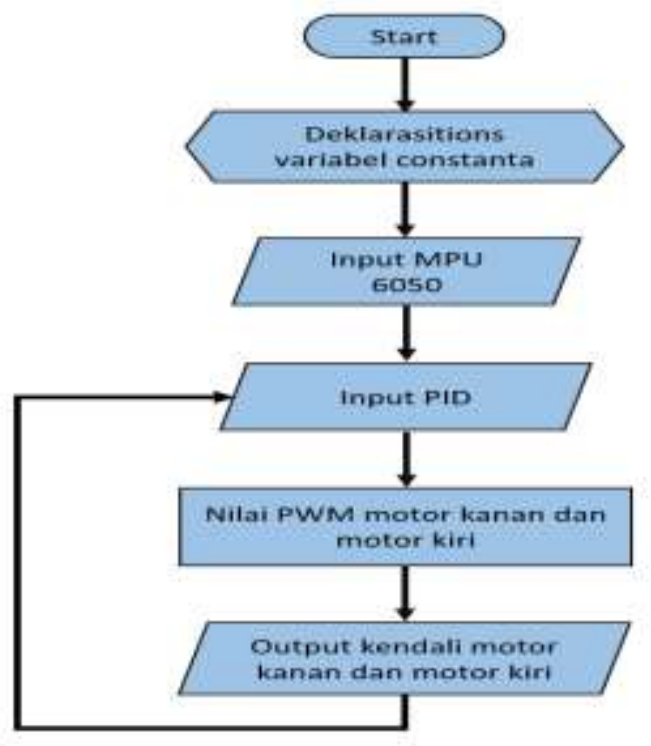

Gambar 7. Flowchart rancangan Balancing Robot

Keterangan flowchart yaitu:

a. Deklarasi variabel konstan

Merupakan tahapan awal dalam persiapan nilai konstan keseluruhan untuk dapat dioperasikan

b. Masukan nilai data MPU

c. Masukan nilai PID (nilai $\mathrm{Kp}, \mathrm{Kp}$, dan $\mathrm{Kd}$ )

d. Nilai dari PWM (Pulse Width Modulation) untuk keluaran mengendalikan motor kanan dan motor kiri

Sistem kontrol PID pada balancing robot diperlihatkan pada Gambar 8.

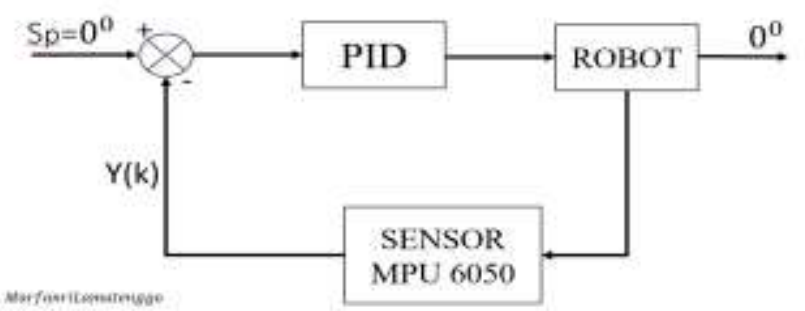

Gambar 8. Diagram Blok Kendali PID Loop Tertutup

Pengendali Proporsional ( $K p)$ akan memberikan efek mengurangi waktu naik, tetapi tidak menghapus kesalahan keadaan tunak, Pengendali Integral $(\mathrm{Ki})$ akan memberikan efek menghapus keadaan tunak, tetapi berakibat memburuknya respon transien, pengendali Diferensial controler $(K d)$ akan memberikan efek meningkatnya stabilitas sistem, mengurangi over-shoot, dan menaikan respon transfer [12-14].

\section{Hasil Pengujian Balancing Robot}

Setelah melakukan pengujian pada masing-masing komponen robot, selanjutnya melakukan pengujian alat 
secara keseluruhan. Karena arah jatuh robot hanya dua arah (dua dimensi), maka yang digunakan hanya dua axis, yaitu axis-Y (sumbu datar) dan axis-Z (sumbu tegak). Pengujian dilakukan dengan cara mengubah manual program pada Axis-Y dan Axis-Z kemudian di amati posisi robot yang berdiri di atas permukaan bidang datar untuk mencari posisi yang tepat untuk seimbang. Tabel 1 menunjukkan hasil pengujian Axis-Y dan Axis-Z pada balancing robot.

TABel 1. Pengujian Axis Y Dan Z Pada Balancing Robot

\begin{tabular}{|c|c|c|}
\hline Pengujian Axis & Y & $\mathrm{Z}$ \\
\hline 1 & 10 & -10 \\
\hline 2 & 20 & -20 \\
\hline 3 & 40 & -40 \\
\hline 4 & 60 & -60 \\
\hline 5 & 80 & -80 \\
\hline 6 & 140 & -140 \\
\hline 7 & 160 & -160 \\
\hline 8 & 180 & -180 \\
\hline 9 & 200 & -200 \\
\hline 10 & 220 & -220 \\
\hline
\end{tabular}

Berdasarkan hasil pengujian yang diubah secara manual dan mengamati posisi robot yang berdiri di atas permukaan bidang datar didapat untuk menyeimbang badan robot diperoleh nilai Axis $\mathrm{Y}$ adalah 220 dan nilai Axis $\mathrm{Z}$ yang didapat untuk menyeimbangkan badan robot dengan nilai Axis $\mathrm{Z}$ adalah -40. Dimana nilai maksimum Axis adalah $2^{16}$ $=65536$.

Setelah mendapatkan posisi yang tepat kemudian mencari nilai PID $(K p, K i$, dan $K d)$ untuk kestabilan posisi robot dengan cara mengubah-ubah nilai parameternya kemudian amati kondisi robot. Berdasarkan hasil pengujian PID yang diubah secara manual dan mengamati posisi robot yang berdiri di atas permukaan bidang datar didapat untuk penstabil robot diperoleh nilai $K p=60$, nilai $K i=2.0$ dan $K d=130$.

\section{KESIMPULAN}

Telah dibuat sebuah model robot beroda dua yang dapat menjaga keseimbangannya (Balancing Robot) pada permukaan datar. Metode pengendali yang digunakan adalah Pengendali Proporsional, Integral, Derivatif (PID). Komponen penyusun model balancing robot adalah Arduino Nano, Motor driver L298N, Motor DC 6V 620rpm, Gearbox 25ga370, dan Baterai Lipo 2200mAh 3S 25C XT60. Balancing robot dapat menyeimbangkan diri pada Axis Y 220 dan Axis Z -40 . Nilai konstanta pengendali PID diperoleh $K p=60, K i=2.0$ dan $K d=130$ sehingga sistem ini mampu menstabilkan posisi robot.

\section{REFFERENSI}

[1] Ketaren dan Rahmawaty, Balancing Robot Beroda Dua Menggunakan Metoda Kontrol Proporsional, Integral dan Derivatif. Jurnal Politeknik Caltex Riau, Vol, 1(2), 39-48, 2015

[2] A.P. Pamungkas, Balancing Robot Beroda Dua Menggunakan Metode Fuzzy Logic, Universitas Dian Nuswantoro, 2013

[3] S. Puspitasari, Implementasi Kontrol Logika Fuzzy Pada Sistem Kesetimbangan Robot Beroda Dua, Teknik Elektro, Universitas Brawijaya, 2014

[4] B. Henryranu, W. Kurniawan, B. Priyambadha, Implementasi Sensor Cahaya Sebagai Pengontrol Keseimbangan Robot Beroda Dua Menggunakan Kontroler PID, Jurnal Teknologi Informasi dan Teknik Menggunakan Kontroler PID, Jurnal Tekn
Komputer Vol, 1(1), 25-28, April 2014

[5] J. Sumanti, A.S.M Lumenta, D. Pang, Kontrol Optimal pada Balancing Robot Menggunakan Metode Linear Quadratic Regulator, e jurnal Teknik Elektro UNSRAT, 2014

[6] G. Bobby, E. Susanto, F.Y. Suratman, Perancangan Dan Implementasi Robot Keseimbangan Beroda Dua Berbasis Implementasi Robot Keseimbangan Beroda
Mikrokontroler, Jurnal Elkomika Vol. 3 No. 2, 2015

[7] B.N. Cahyono, B. Setiyono, Sumardi. Self-Balancing Scooter Menggunakan Metode Pengendali Proporsional Integral Derivatif. Jurnal Transmisi, Vol. 15 (4) 2013, 164-169.

[8] F.R. Usman, W. Ridwan, I.Z. Nasibu, Sistem Peringatan Dini Bencana Banjir Berbasis Mikrokontroler Arduino, Jambura Journal of Electrical and Electronics Engineering, Vol. 1 No. 1 Januari 2019.

[9] F. Tahir, W. Ridwan, I.Z. Nasibu, Monitor Kualitas Udara Berbasis Web Menggunakan Raspberry

[10] Y.H. Kanoi, S. Abdussamad, S.W. Dali, Perancangan Jam Digital Waktu Sholat Menggunakan Arduino Uno, Jambura Journal of Electrical and Electronics Engineering, Vol. 1 No. 2 Juli 2019.

[11] I. Wiranto, Perancangan Sistem Kontrol Hovercraft Menggunakan Metode Pole Placement Sistem Servo, Jurnal Teknik Vol. 6 No. 1, Juni 2008.

[12] W. Ridwan, Bahan Ajar Dasar Sistem Kontrol, Teknik Elektro Universitas Negeri Gorontalo, 2013

[13] I. Wiranto, Perancangan dan Simulasi Kontroler PID Pada Plant Tenaga Surya Menggunakan MATLAB, Jurnal Teknik Vol. 11 No. 2, Desember 2013.

[14] W. Ridwan, Penerapan Kendali Logika Fuzzy+Proportional Integral Pada Modul Process Control Simulator PCS 327 MK2, Jurnal Teknik Vol.8, No. 1, April 2009. 